\title{
Multiple de novo copy number variations in two subjects with developmental problems and multiple congenital anomalies
}

\author{
Pengfei Liư ${ }^{1 *}$, Klaudia Walter ${ }^{4}$, Karin Writzl ${ }^{5}$, Violet Gelowani ${ }^{1}$, Sarah Lindsay ${ }^{4}$, Claudia MB Carvalho ${ }^{1}$, \\ Marjorie Withers ${ }^{1}$, Joanna Wiszniewska ${ }^{1}$, Ankita Patel ${ }^{1}$, Bernd Rautenstrauss ${ }^{6}$, Matthew E Hurles ${ }^{4}$, \\ James R Lupski ${ }^{1,2,3}$
}

From Beyond the Genome 2012

Boston, MA, USA. 27-29 September 2012

\section{Background}

De novo copy number variation (CNV) can occur constitutionally in gametogenesis or in early development leading to sporadic genomic disorders. Such de novo CNVs appear to also be important in somatic mutagenesis relevant to cancer and population events important to species evolution. Since large pathological CNVs are rarely observed at more than one locus in a single patient, and are often de novo, current efforts in understanding their molecular features and underlying mechanisms have relied on comparing CNVs from different individuals. Therefore, knowledge regarding size, mechanism and spatial distribution of de novo genomic rearrangements in a single genetic background is lacking.

\section{Materials and methods}

Two subjects with developmental problems and multiple congenital anomalies were identified by clinical array comparative genomic hybridization $(\mathrm{aCGH})$ to have more than five de novo CNVs larger than $500 \mathrm{~kb}$. Custom-designed aCGH and whole genome SNP arrays were used to fine map large de novo CNVs in both of the subjects and determine parental origins, whereas breakpoint sequencing was performed to glean insights into mechanism. In order to characterize smaller sized CNVs not efficiently interrogated by aCGH, Illumina whole genome sequencing was performed on both subjects to obtain a sequence coverage of more than $30 x$.

Department of Molecular and Human Genetics, Baylor College of Medicine, Houston, TX, USA

Full list of author information is available at the end of the article

\section{Results}

We report two subjects with a constitutional 'CNV mutator' phenotype, in whom multiple de novo rearrangements were observed on different chromosomes. Such observations are distinguishable from the phenomenon of chromothripsis in which the multiple $\mathrm{CNV}$ changes concentrate on one chromosome [1]. Subject no. 1 carried 8 large (>100 kb) copy number gains, ranging from $104 \mathrm{~kb}$ to 6.4 Mb. Subject no. 2 carried 11 large copy number gains, ranging from $211 \mathrm{~kb}$ to $4.7 \mathrm{Mb}$. Breakpoint sequencing analysis showed that microhomologies and breakpoint complexities are the prevailing features left at rearrangement traces, suggesting that the rearrangements were likely produced by replication mechanisms such as fork stalling and template switching and/or microhomology-mediated break-induced replication (FoSTeS/MMBIR). Haplotype analysis in subject no. 1 revealed that the duplicated or triplicated materials were derived from both the paternal chromosome and the maternal chromosome, suggesting a postzygotic timing of the mutations.

\section{Conclusions}

Our results document a genome-wide spectrum of de novo CNVs in a 'CNV mutator' phenotype background, and we suggest that errors in the cellular DNA replication machinery could lead to multiple independent de novo rearrangements. Our findings have important implications for genomic disorders, cancer and evolution.

\footnotetext{
Author details

${ }^{1}$ Department of Molecular and Human Genetics, Baylor College of Medicine, Houston, TX, USA. ²Department of Pediatrics, Baylor College of Medicine, Houston, TX, USA. ${ }^{3}$ Texas Children's Hospital, Houston, TX, USA.
} 
${ }^{4}$ Wellcome Trust Sanger Institute, Hinxton, UK. ${ }^{5}$ Institute of Medical Genetics, UMC, Ljubljana, Slovenia. ${ }^{6}$ Medical Genetics Center, Bayerstrasse 3-5, Munich, Germany.

Published: 1 October 2012

\section{Reference}

1. Liu P, Carvalho CM, Hastings P, Lupski JR: Mechanisms for recurrent and complex human genomic rearrangements. Curr Opin Genet Dev 2012, 22:211-220.

doi:10.1186/1753-6561-6-S6-P25

Cite this article as: Liu et al:: Multiple de novo copy number variations

in two subjects with developmental problems and multiple congenital anomalies. BMC Proceedings 2012 6(Suppl 6):P25.

Submit your next manuscript to BioMed Central and take full advantage of:

- Convenient online submission

- Thorough peer review

- No space constraints or color figure charges

- Immediate publication on acceptance

- Inclusion in PubMed, CAS, Scopus and Google Scholar

- Research which is freely available for redistribution

Submit your manuscript at www.biomedcentral.com/submit
Ciomed Central 